\title{
Can a Child Feel Responsible for Another in the Presence of a Robot in a Collaborative Learning Activity?
}

Conference Paper · October 2015

DOI: 10.1109/ROMAN.2015.7333678

CITATIONS

4

6 authors, including:

\section{Shruti Chandra}

École Polytechnique Fédérale de Lausanne

4 PUBLICATIONS 6 CITATIONS

SEE PROFILE

Ana Paiva

Instituto Superior Técnico, Inesc-ID

406 PUBLICATIONS $\quad \mathbf{4 , 7 7 4}$ CITATIONS

SEE PROFILE
READS

114

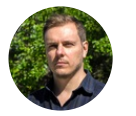

Pedro Sequeira

Northeastern University

24 PUBLICATIONS 163 CITATIONS

SEE PROFILE

Pierre Dillenbourg

École Polytechnique Fédérale de Lausanne 357 PUBLICATIONS 9,816 CITATIONS

SEE PROFILE

Some of the authors of this publication are also working on these related projects:

Project Cellulo View project

Project The Robot-Creativity Project View project

All content following this page was uploaded by Patrícia Alves-Oliveira on 23 November 2015.

The user has requested enhancement of the downloaded file. All in-text references underlined in blue are added to the original document and are linked to publications on ResearchGate, letting you access and read them immediately. 


\title{
Can a Child Feel Responsible for Another in the Presence of a Robot in a Collaborative Learning Activity?
}

\author{
Shruti Chandra, ${ }^{1}$ Patrícia Alves-Oliveira, ${ }^{2}$ Séverin Lemaignan, ${ }^{3}$ \\ Pedro Sequeira, ${ }^{2}$ Ana Paiva, ${ }^{2}$ and Pierre Dillenbourg ${ }^{3}$
}

\begin{abstract}
In order to explore the impact of integrating a robot as a facilitator in a collaborative activity, we examined interpersonal distancing of children both with a human adult and a robot facilitator. Our scenario involves two children performing a collaborative learning activity, which included the writing of a word/letter on a tactile tablet. Based on the learning-by-teaching paradigm, one of the children acted as a teacher when the other acted as a learner. Our study involved 40 children between 6 and 8 years old, in two conditions (robot or human facilitator). The results suggest first that the child acting as a teacher feel more responsible when the facilitator is a robot, compared to a human ; they show then that the interaction between a (teacher) child and a robot facilitator can be characterized as being a reciprocity-based interaction, whereas a human presence fosters a compensationbased interaction.
\end{abstract}

\section{INTRODUCTION}

Robots have been used with children to seek new methods of learning in education. Research in educational robotics has proven its significance in several areas of education such as programming, science, design, mathematics, and games [1]. Also, robots are used to play different roles in the education context, such as a tutor, an assistant, a learner, among others. For example, Kanda et al. [2] used Robovie, a humanoid robot, as a social partner and peer tutor in a field trial. That study showed that robots can form relationships with children, and also that children may learn from robots as they learn from their peers. In addition, the EMOTE project (http://www.emote-project.eu/), a European project which aims to create a robotic tutor with empathic capabilities, is also exploring the role of robots as tutors to assist learners, specifically addressing the role of empathy in education [3, 4].

Significant work on educational robotics adopt a collaborative setting where both learners and robots interact. In such settings, specific types of interactions (e.g. prompts by the participants over each other's performances) between participants are expected to occur. Yet, there is no guarantee

\footnotetext{
${ }^{1}$ Shruti Chandra is with the École Polytechnique Fédérale de Lausanne, Switzerland and Instituto Superior Técnico, University of Lisbon, Portugal (phone: +351-214233517; fax: +351-214233290. E-mail: shruti.chandra@tecnico.ulisboa.pt.

${ }^{2}$ Patrícia Alves-Oliveira, Pedro Sequeira and Ana Paiva are with INESC-ID and Instituto Superior Técnico, University of Lisbon, Portugal. E-mail: patricia.alves.oliveiralinesc-id.pt, pedro.sequeiraegaips.inesc-id.pt, ana.paivalinesc-id.pt.

${ }^{3}$ Séverin Lemaignan and Pierre Dillenbourg are with the École Polytechnique Fédérale de Lausanne, Switzerland. E-mail: severin.lemaignan@epfl.ch, pierre.dillenbourg@epfl.
}

that these interactions will actually occcur. However, we can increase the probability of the occurrence of these interactions by setting up the initial conditions, by specifying the roles of participants in the scenario, or by controlling and monitoring the interactions [5]. Learning-by-teaching has been shown to be an effective method to support learning. This approach allows students to prepare and teach lessons in their own way. In addition to preparation of lessons, the teaching process includes three aspects of learning interactions: structuring, taking responsibility, and reflecting [6]. This study also shows that the students who teach acquire profound knowledge about the domain and are able to express their ideas more clearly than those who learn the same material by writing a summary. As illustrated in [7], participants who teach other participants about a passage scored more in a quiz comparing with those who did not. Tanaka and Matsuzoe [8] used the NAO $\operatorname{robot}^{1}$ as a care receiving interactive agent. In their work, children taught the robot using the learning-by-teaching method and the results suggested that the care-receiving robot contributed to the enhancement of the children spontaneous learning and motivation. Hood et al. [9] also used NAO robot where children taught handwriting to the robot and the interaction could stimulate metacognition, empathy and increased self esteem of the child user.

\section{BACKGROUND}

In the learning-by-teaching paradigm, interactions between learners can lead to more responsibility and reflection. For the purposes of this work, we will focus on the notion of responsibility in human-robot interaction (HRI) and explore it with a concrete scenario where two children (one acting as a teacher and another as a learner) interact with the help of a facilitator, which can be either a robot or a human. Responsibility in teaching relates the way a teacher responds in a particular moment to a particular student [10]. Additionally, responsibility can be related with the type of feedback given by the teacher to the student. This study explores the verbal feedback given by the teacher-child to the learner-child over the latter's performance in writing, in the presence of a facilitator (a robot or a human).

Furthermore, when designing interactions with robots, one of the critical elements is proxemics - the amount of physical and psychological space that people feel necessary to set between themselves and others [11]. Research in human

\footnotetext{
${ }^{1}$ Aldebaran robotics: https://www. aldebaran.com/en.
} 


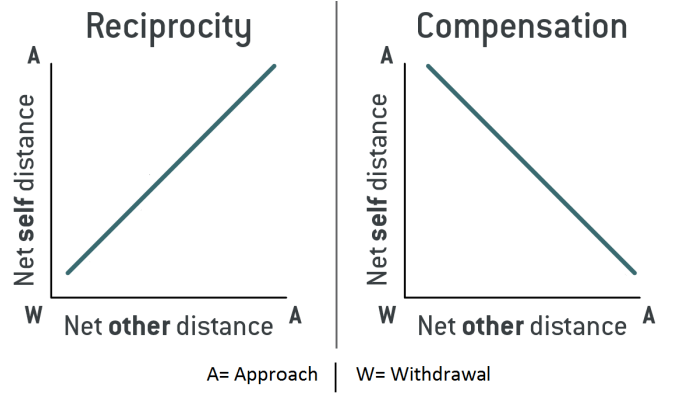

Fig. 1: Reciprocity and Compensation models of interpersonal distancing (adapted from [16]).

proxemics has been extensively studied and models have been developed to explain human-robot behaviour in terms of verbal and non-verbal communication [12]. In this study we will use two models for the characterization of the psychological proximity established with a robot, namely the reciprocity and the compensation models (see Fig. 1 for a comparison between the models).

Reciprocity model: This model explains the psychological and interpersonal distance between people. According to this model, during an interaction, when one person decreases the distance (or increases closeness), the other reciprocates by increasing the closeness $[13,14]$. For example, if one person maintains eye contact with another for a long time, the other would verbally disclose more in return. Jourard and Friedman [13] evidenced a linear relationship between the participant's self-disclosure and the experimenter's verbal disclosure.

Compensation (or Equilibrium) Model: According to the Compensation model developed by Argyle and Dean [15] there is an equilibrium for physical proximity and eye contact between two individuals. If this equilibrium is disturbed in one of its constituent dimensions, e.g. by increasing physical proximity there will be complementary changes along the other dimensions. For example, if one person maintains eye contact to another person only for short time duration, the other person will verbally disclose more. Here, distancing is considered in terms of eye contact, physical proximity, intimacy of the topic, amount of smiling.

In the work reported here, these two models were chosen as a way to analyze and understand how children's interpersonal distance varies in the presence of either a robot or a human facilitator during a collaborative learning activity.

\section{THE STUDY}

Physical and psychological distancing in HRI is one of the important factors that facilitate interaction. Although some studies have explored physical distancing in HRI [17, 18], less attention has been given to the interpersonal distancing, specifically in child-robot interaction (CRI) [12].

In the current study, we sought to provide a contribution to the HRI field by using models of interpersonal distancing, i.e. the reciprocity and compensation models, in terms of verbal and non-verbal cues in an educational context. In order to examine the impact of a robot versus a human facilitator regarding interpersonal distancing, this study consists of a between-subjects design with two conditions: one in which a pair of children performs a collaborative learning activity with a robot facilitator, and another where the same activity is performed with a human facilitator. In both conditions, the learning-by-teaching method was used by assigning a different role to each child: either that of a teacher or a learner. The teacher-child was then asked by the facilitator to provide corrective feedback [19] on the performance of the learner-child.

In the experimental design, the dynamics between the study participants is triadic but the interaction between the children is dyadic. Since the study was conducted with 6 to 8 years old children, the role of the facilitator was to support the interaction flow between children. In order to exploit the benefits of the learning-by-teaching method, we want to explore the dyadic interactions between the children in the presence of both a robot and a human facilitator. The validation of the study also includes the analysis of the learning gains in both conditions.

Overall, the goal of this paper concerns the study of children's responsibility given the assigned roles in a collaborative learning activity. In addition, we studied the children's models of interpersonal distancing that emerged in the presence of a human or robot facilitator during the interaction. Our hypotheses for the study are:

- H1: The child who plays a role of teacher will express more responsibility in a condition where the robot is present by the type of feedback provided over the performance of the learner-child.

- H2: Given that the facilitator (robot or human) provides equal information to the children, the learning gains will not differ in both conditions.

\section{Method}

\section{A. Participants}

The study was conducted with 40 Portuguese speaking children in the age group 6 to 8 years ( $1^{\text {st }}$ and $2^{\text {nd }}$ grade). The study was performed in a Portuguese school and followed the ethical norms of privacy and responsibility of HRI studies. As such, only children who assented for the study and whose parents signed the informed consent participated.

\section{B. Materials}

The materials used in the study consisted of two tactile tablets installed with a custom writing application. This application was developed specifically for this study and displays the writings of each child on each other's tablet, so that they can correct each other on their own tablet in real-time. In addition, two stylus were used for children to write as similarly as they learn in school. Also, we created 4 colorful cards written with $\mathrm{h}$, Lua ${ }^{2}$ (moon), gelado (icecream), and Rainbow. For the pre- and post-test we used a sheet with letters (j, D, K, y, W, t, $\alpha$, and $\pi$ ). In terms of the technical setup, 3 video cameras, 2 lavalier microphones and a NAO torso as the robot facilitator were used.

\footnotetext{
${ }^{2}$ As the study was performed in a Portuguese school, Lua and gelado were written in the Portuguese language.
} 
(a) Overview

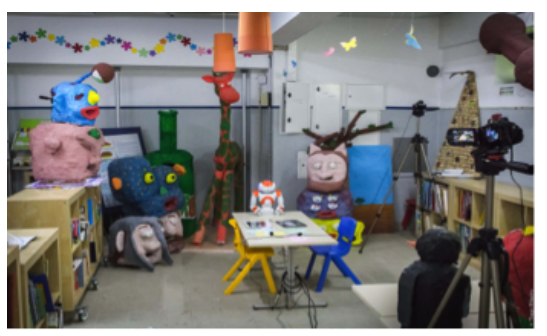

(b) Robot condition

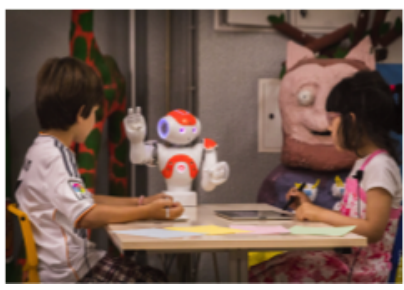

Fig. 2: Setup for the study: (a) classroom overview; (b)-(c) children with the robot and the human facilitator.

\section{Design of the Study}

As mentioned earlier, we performed our study over two different conditions:

Condition 1: A robot acts as a learning facilitator and interacts with the two children during a collaborative educational activity designed according to the learning-by-teaching method (one child played the role of the teacher while the other the role of the learner).

Condition 2: This condition is similar to Condition 1 but instead of using a robot as the learning facilitator, a human facilitator was included.

Each session was performed with a pair of children and a facilitator according to one of the conditions and lasted between 15-20 minutes. We used a Wizard-of-Oz (WoZ) procedure in which a robot is remotely controlled by a human, referred to as the Wizard, when interacting with a research participant. The participants are unaware that the robot is being remotely controlled, and the method is commonly used within the field of HRI [20]. In our study, a psychologist present in the classroom where the study took place but hidden from the participants, acted as the Wizard. Before initiating the experiment, the human facilitator went through a training phase to memorize the predefined script. Therefore, both the human and robot facilitator used the same script during the study. In the human condition, whenever a child asked questions to the facilitator, she gave neutral answers as to avoid discrepancies between the conditions. Condition 1 was performed with 24 children (12 pairs) and the Condition 2 with 16 children (8 pairs). Fig. 2 shows the classroom setup of the study, including the two conditions.

\section{Procedure}

All children performed a pre- and a post-test, i.e. before and after the learning activity with the facilitator. The study was thus organized in three main phases:
Phases 1 \& 3: Pre- and post-test: In this phase a researcher asked the two children to individually copy the given letters (j, D, K, y, W, t, $\alpha$ and $\pi$ ) on a paper sheet. This activity served as a pre-test and was repeated after Phase 2 thus serving also as a post-test.

Phase 2: Learning activity with the facilitator: After having completed the pre-test, the children were guided to the study setup in the same classroom and were instructed to sit around the table with the facilitator. The researcher explained that they were going to perform a collaborative writing activity on a tactile tablet with a robot/human facilitator. The researcher then left the room, leaving the children with the facilitator. The interaction pattern of the learning activity in both conditions of the study progressed as follows:

1) Welcome greeting: The first step of the interaction pattern concerned the introduction of the facilitator and the children. Given the very young age of the children, this step was especially important in condition 1 , as most children had never seen a robot before and needed some familiar ground to start the interaction.

2) Tutorial: The second step concerned the explanation of the activity to the children by the facilitator. Following the explanation, the facilitator assigned two roles to the children: one child was instructed to play the role of a teacher and the other the role of a learner. Roles were randomly assigned by the researcher. Following the learning-by-teaching method of education, the learner-child wrote the letters and words on the tactile tablet, while the teacher-child was responsible to provide corrective feedback on the task performance of the learner-child in whatever ways were possible, e.g. by writing on the tablet a correction, or by verbally expressing it. During the writing activities, the facilitator ensured the educational interaction between the children would flow smoothly. After this tutorial part, some time was reserved for the children to draw freely on the tablet in order to make them familiar with the application dynamics. Moreover, the assigned roles of the children were not altered throughout the session to make the interaction simpler for them.

3) Collaborative learning activity: The third step of the interaction pattern was dedicated to the learning activity between children and the facilitator. During the writing task, four different coloured cards with a different letter or words were placed on the table facing down. As the activity progressed, the facilitator asked the teacher-child to pick a card and show it to the learner-child so that he/she could write the letter or word on the tablet application. After the learnerchild finished writing such letter/word, the teacher-child was instructed to provide corrective feedback. After that, the facilitator prompted the teacher-child to ensure that all corrections were provided. This process then repeated until all 4 coloured cards were picked. The cards were introduced with increased difficulty level, i.e. by increasing the word length. The last card to be picked was the word Rainbow as it represented the longest and unknown (English) word.

4) Goodbye greeting: The activity was terminated by having the facilitator thank the children for their time. 
TABLE I: Verbal Behaviour.

\begin{tabular}{l|l|l}
\hline $\begin{array}{l}\text { Verbal } \\
\text { behaviour }\end{array}$ & Definition & Example \\
\hline $\begin{array}{l}\text { Corrective } \\
\text { Feedback } \\
\text { (minimal) }\end{array}$ & $\begin{array}{l}\text { Minimal response re- } \\
\text { lated to the correc- } \\
\text { tions of the letters and } \\
\text { words. }\end{array}$ & $\begin{array}{l}\text { Facilitator: Is the shape of } \\
\text { the letter } \text { is correct? } \\
\text { Teacher-child: Yes }\end{array}$ \\
$\begin{array}{l}\text { Corrective } \\
\text { Feedback } \\
\text { (extended) }\end{array}$ & $\begin{array}{l}\text { Extended response re- } \\
\text { lated to the corrections } \\
\text { of letters and words. }\end{array}$ & $\begin{array}{l}\text { Facilitator: Is the shape of } \\
\text { the letter } \text { is correct? } \\
\text { Teacher-child: } \text { No, it's not. } \\
\text { This part should be round. }\end{array}$ \\
\hline
\end{tabular}

\section{RESULTS}

In order to analyse the several interactions we performed video and audio analysis of all the sessions by coding and annotating different verbal (corrective feedback) and nonverbal (Gaze) behaviours of both children and the facilitator. The annotations were performed with two independent coders using the ELAN multimedia annotation tool. ${ }^{3}$ In addition to this, pre- and post-test sheets were also graded by the coders. In terms of the reliability of the participants' behaviours, Cohen's kappa showed 0.84 of agreement for verbal behaviour, 0.92 for the gaze behaviour and 0.96 for the pre- and post-test sheet grading, indicating a good agreement. Welch Two-Sample t-test was further conducted to analyse both verbal behaviour and non-verbal of the facilitator and the children. The annotated behaviours are detailed in Tables I-II.

\section{A. Responsibility in Teaching}

Corrective feedback is the response regarding the corrections made by a child upon the performance of another child. Table I defines and gives examples of the types of corrective feedback annotated. In our study, the feedback given by children was evaluated either as minimal or extended according to $[19,21]$. Although most of the feedback was directed through the facilitator (given the several questions made during the activities), it is important to consider the dyadic interaction between children in which the feedback relates the other child's performance. Therefore, we considered the corrective feedback provided by the teacher-child to the learner-child as a response through the facilitator. An example of interaction is given below.

The learner-child finishes writing a word:

Facilitator: Do you think the word is written correctly?

Teacher-child: No, I think it should be more curved here and written in the same size.

After the corrective feedback given by the teacher-child, learner-child addresses the corrections on the tablet.

The result of Welch's Two-sample t-test between the two study conditions suggests that the teacher-child gave more extended corrective feedback to the learner-child through

\footnotetext{
${ }^{3}$ https://tla.mpi.nl/tools/tla-tools/elan/
}

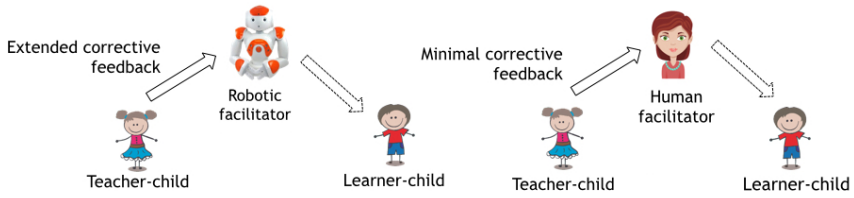

Fig. 3: Extended and minimal corrective feedback in the robot and human conditions.

the robot facilitator $(d f=20.373,95 \% \mathrm{CI}[-2.60,-0.29])$; $t=-2.6071, p=0.01671, M($ Learner-child $)=0.15$, $M($ Teacher-child) $=1.66$ (see Fig. 4(a)). On the other hand, we found that the teacher-child gave more minimal corrective feedback to the learner-child through the human facilitator $(d f=23.0,95 \% \mathrm{CI}[-2.3779970-0.1066184])$; $t=-2.2625, p=0.03339, M($ Learner-child $)=0.30$, $M($ Teacher-child $)=1.5$ (Fig. 4(a)).

Because the teacher-child was instructed to play the role of a teacher, we already expected that all teacher-children would provide more corrective feedback in comparison with the learner-children. Nevertheless, the interest of the results regarding corrective feedback lies on the type of the feedback (minimal or extended) that the teacher-child provided to the learner-child in both conditions (Fig. 3). In that respect, the teacher-children provided more extended feedback to the learner-children in the robot condition-this suggests that the teacher-children felt more responsible over the performance of learner-children in the presence of the robot facilitator, thus supporting our first study hypothesis. Further discussion is provided in Section VI.

\section{B. Interpersonal Models of Interaction in Education}

Interpersonal models of interaction were analysed by combining the results concerning the corrective feedback provided above and following analysis of gaze.

Gaze of the facilitator: The gaze behaviours of the robot and human facilitators towards the children were analysed in terms of nature (Table II) and duration. The eye-gaze model of the robot was restricted due to its embodiment, e.g. when the robot asked a question to one child, it would look at them for the required time by moving only its head instead of being able to perform gaze shifts with its eyes. In contrast, in the human condition there was no constraint for gazing at children, resulting in a natural gaze behaviour.

Results show that, in comparison with the human facilitator, the robot facilitator gazed for a longer time both to the teacher-child ( $d f=17.88,95 \% \mathrm{CI}[-0.26,-0.18])$; $t=-11.2409, p=1.547 \mathrm{e}^{-9}, M($ Human $)=0.14$, $M($ Robot $)=0.37$, and the learner-child $(d f=16.069$, $95 \% \mathrm{CI}[-0.20,-0.12]) ; t=-8.7743, p=1.585 \mathrm{e}^{-7}$, $M($ Human $)=0.14, M($ Robot $)=0.30$. Fig. 4(b) shows the average duration of the gaze of the facilitators to the children in gazing seconds per minute of interaction, normalized according to the length of each session: For instance, the human facilitator gazed $0.14 \mathrm{sec} / \mathrm{min}$ to the learner-child while spending $0.86 \mathrm{sec} / \mathrm{min}$ looking at the task or elsewhere. 
(a) Teacher- and learner-child feedback

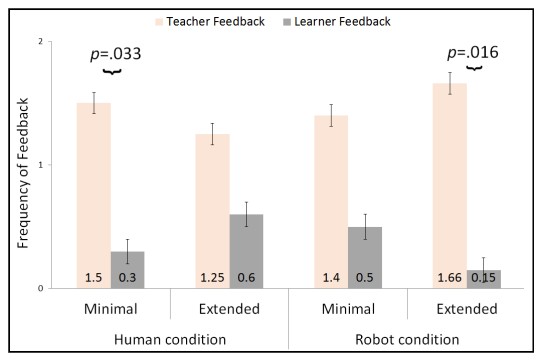

(b) Gaze duration

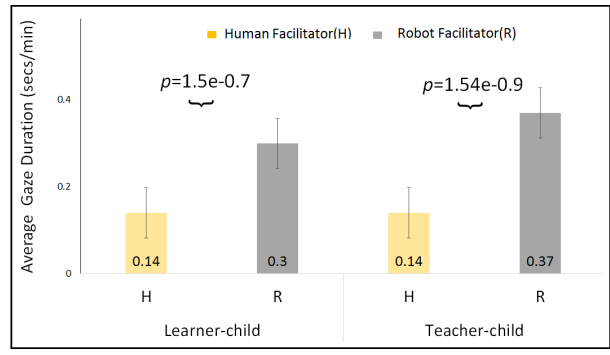

(c) Tasks durations

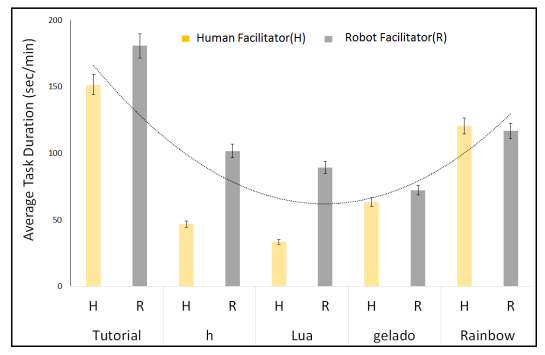

Fig. 4: Results of the study: (a) teacher-child and learner-child corrective feedback; (b) gaze duration of the facilitator (robot/human) to the learner-child and the teacher-child; (c) tasks durations across the study conditions.

TABLE II: Non-verbal Behaviour (Gaze).

\begin{tabular}{|c|c|}
\hline Gaze Behaviour & Definition \\
\hline Gaze at task & $\begin{array}{l}\text { When children or the facilitator look at task, } \\
\text { e.g. tablet, stylus, sheets. }\end{array}$ \\
\hline $\begin{array}{l}\text { Gaze at } \\
\text { participants }\end{array}$ & $\begin{array}{l}\text { When children look at human or robot facil- } \\
\text { itator. } \\
\text { When the facilitator looks at children } \\
\text { (teacher-child or learner-child). } \\
\text { When children look at each other. }\end{array}$ \\
\hline Gaze elsewhere & When participants look elsewhere. \\
\hline
\end{tabular}

Interpersonal distance: We computed the interpersonal distance between the children and the facilitator by relating the results of the facilitator's gaze and the children's corrective feedback. The gaze results of this analysis are depicted in Fig. 4(b) and suggest that the robot facilitator looked longer while asking questions to both children, compared with the human facilitator. In addition, the teacher-children provided more extended corrective feedback to the learner-children through the robot facilitator (Fig. 4(a)) - in this manner, the interaction between the robot and the teacher-child seems to follow the reciprocity model of interpersonal distancing. On the other hand, the human facilitator looked for a shorter duration to both children and all teacher-children gave more minimal corrective feedback over the learner's performance through the human facilitator-as a result, the interaction between the human facilitator and teacher-child seems to follow the compensation model of interpersonal distancing. Overall, these results suggest that the different interpersonal models could emerge depending on the facilitator.

Learning gains analysis: In order to analyze how the presence of robot or human facilitators affects the learning of children, we compared the learning gains between the pre-test and post-test across the two conditions. Pre- and post-test sheets were graded by giving a score to each letter written by children in the sheets. The results are depicted in Fig. 5(a) and indicate that overall there was a significant difference between the learning gains in the pre-test and the post-test, $(d f=72.15, \mathrm{CI}=[1.47,3.42]) ; t=5.0297$, $p=3.465 \mathrm{e}^{-6}, M$ (Post-test $)=14.57, M$ (Pre-test $)=12.12$, which indicates that all children improved in the post-test (a) Pre-/post-tests
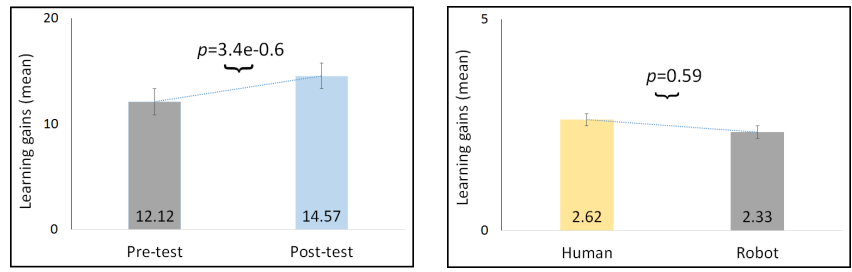

Fig. 5: Results of the learning gains in the: (a) pre- and post-tests; (b) human and robot conditions.

comparing with the pre-test. By analysing the learning gains between conditions in Fig. 5(b), results show no significant difference in learning gains between the human and robot condition $(d f=36.6, \mathrm{CI}=[-0.79,1.37]) ; t=0.543$, $p=0.59, M($ Human $)=2.6, M($ Robot $)=2.3$. The results of this analysis thus supports our second hypothesis.

\section{Task Progression}

In order to study whether the progression in the learning activity for both teacher- and learner-children was similar in the presence of a robot or human facilitator, we analysed the duration time of each task-step. The duration of each task-step was measured in the following manner:

- Tutorial: Duration measured from drawing start to the first coloured card was picked;

- H, Lua, Gelado, Rainbow: Duration measured whenever a card was picked until the next card was picked.

Additionally, the task-steps duration contained all the interactions, e.g. corrections, instructions by facilitator, etc. The average duration is depicted in Fig. 4(c) showing the task approach of children in the presence of different facilitators. It also presents the relation between the task-step difficulty levels and the time spent finishing them. The results suggest that the task progression pattern with a robot facilitator was similar to the pattern with a human. Furthermore, it indicates that the children's approach to the overall task is the same irrespective of different facilitators. Moreover, Fig. 4(c) shows there is a pattern in terms of the duration of task-step, suggesting a relation between each task-step difficulty level and the time spent on it, i.e. that children spent more time on the task-step related with more difficult levels. 


\section{CONCLUSION}

The goal of this paper was to explore the child's responsibility in a collaborative learning activity using the learningby-teaching method in the presence of either a robot or a human facilitator.

The results of the study suggest that the teacher-children felt more responsible over the learner-children's performance in the presence of robot facilitator. In this context, responsibility is concerned with the type of verbal feedback given by the teacher-child to the learner-child. Verbal feedback is an expression of responsibility that shows the teacherchild's engagement with the learner-child. Extended corrective feedback increases this engagement in comparison with the minimal corrective feedback as more information is provided to the learner-child on his/her performance. As a result of our study, teacher-children expressed more responsibility in the presence of the robot as he/she provided more extended corrective feedback.

Also, results showed that there is no significant difference in the learning gains between the robot and human condition, revealing a similar learning pattern in both conditions. The emergence of different interpersonal models was also studied during a collaborative learning activity in the presence of different facilitators. In that respect, the results suggest that by having a robot facilitator, a reciprocity model of interaction emerged [11, 12], thus showing the presence of reciprocity and closeness between the children and the robot facilitator. The reciprocity also indicated an increased verbal behaviour (extended corrective feedback) by the children as a response to the robot's increased gaze behaviour. On the other hand, by having a human facilitator, a compensation model of interaction emerged, indicating an increase in the children's verbal behaviour (minimal corrective feedback) related with human's decreased gaze behaviour [11, 12].

Establishing and maintaining the appropriate interpersonal distance may increase the fluidity in interactions with the robot [12]. In that respect, the interpersonal models emerged in this study will support the design of more rich behaviors of robots in educational scenarios. At the same time, the results of this study pose questions suitable for further investigation, e.g. in the same scenario, which models would emerge when the roles of the children are the same? Would the same interpersonal models emerge with different robot embodiments? In the future, we plan to address such questions in order to understand how these models could vary in different educational scenarios.

\section{ACKNOWLEDGMENT}

This work was supported by national funds through Fundação para a Ciência e a Tecnologia (FCT) with reference UID/CEC/50021/2013. The first author acknowledges grant SFRH/BD/51935/2012 from the FCT. The authors show their gratitude to 'Escola 31 de Janeiro' in Parede, Portugal, for taking part in this research. Without the collaboration of the school principal, all involved teachers, children and parents, this study would not have been possible.

\section{REFERENCES}

[1] J. Johnson, "Children, robotics, and education," Artificial Life and Robotics, vol. 7, no. 1-2, pp. 16-21, 2003.

[2] T. Kanda, T. Hirano, D. Eaton, and H. Ishiguro, "Interactive robots as social partners and peer tutors for children: A field trial," HumanComputer Interaction, vol. 19, no. 1, pp. 61-84, Jun. 2004.

[3] A. Deshmukh, G. Castellano, A. Kappas, W. Barendregt, F. Nabais, A. Paiva, T. Ribeiro, I. Leite, and R. Aylett, "Towards empathic artificial tutors," in Proceedings of the 8th ACM/IEEE International Conference on Human-robot Interaction, ser. HRI '13. Piscataway, NJ, USA: IEEE Press, 2013, pp. 113-114.

[4] G. Castellano, A. Paiva, A. Kappas, R. Aylett, H. Hastie, W. Barendregt, F. Nabais, and S. Bull, "Towards empathic virtual and robotic tutors," in Artificial Intelligence in Education, ser. Lecture Notes in Computer Science, H. Lane, K. Yacef, J. Mostow, and P. Pavlik, Eds. Springer Berlin Heidelberg, 2013, vol. 7926, pp. 733-736.

[5] P. Dillenbourg, "What do you mean by collaborative learning?" Cognitive and Computational Approaches, pp. 1-19, 1999.

[6] G. Biswas, K. Leelawong, K. Belynne, K. Viswanath, N. Vye, D. Schwartz, and J. Davis, "Incorporating self regulated learning techniques into learning by teaching environments," in The 26th Annual Meeting of the Cognitive Science Society, 2004, pp. 120-125.

[7] J. A. Bargh and Y. Schul, "On the cognitive benefits of teaching." Journal of Educational Psychology, vol. 72, no. 5, pp. 593-604, 1980.

[8] F. Tanaka and S. Matsuzoe, "Children teach a care-receiving robot to promote their learning: Field experiments in a classroom for vocabulary learning," Journal of Human-Robot Interaction, vol. 1, no. 1,2012

[9] D. Hood, S. Lemaignan, and P. Dillenbourg, "When children teach a robot to write: An autonomous teachable humanoid which uses simulated handwriting," in Proceedings of the 2015 Human-Robot Interaction Conference, 2015.

[10] S. Sherman, "Responsiveness in teaching: Responsibility in its most particular sense," The Educational Forum, vol. 68, no. 2, pp. 115-124, 2004.

[11] E. T. Hall and E. T. Hall, The hidden dimension. Anchor Books New York, 1969, vol. 1990.

[12] J. Mumm and B. Mutlu, "Human-robot proxemics: Physical and psychological distancing in human-robot interaction," in Proceedings of the 6th International Conference on Human-robot Interaction, ser. HRI '11. New York, NY, USA: ACM, 2011, pp. 331-338.

[13] S. M. Jourard and R. Friedman, "Experimenter-subject "distance" and self-disclosure." Journal of Personality and Social Psychology, vol. 15, no. 3 , p. $278,1970$.

[14] A. W. Gouldner, "The norm of reciprocity: A preliminary statement," American Sociological Review, vol. 25, no. 2, pp. 161-178, 1960.

[15] M. Argyle and J. Dean, "Eye-contact, distance and affiliation," Sociometry, vol. 28, no. 3, pp. 289-304, 1965.

[16] K. J. Kaplan, I. J. Firestone, K. W. Klein, and C. Sodikoff, "Distancing in dyads: A comparison of four models," Social Psychology Quarterly, vol. 46, no. 2, pp. 108-115, 1983.

[17] L. Takayama and C. Pantofaru, "Influences on proxemic behaviors in human-robot interaction," in IEEE/RSJ International Conference on Intelligent Robots and Systems, 2009. IROS 2009., St. Louis, USA, Oct 2009, pp. 5495-5502.

[18] M. Walters, K. Dautenhahn, R. te Boekhorst, K. Koay, C. Kaouri, S. Woods, C. Nehaniv, D. Lee, and I. Werry, "The influence of subjects' personality traits on personal spatial zones in a human-robot interaction experiment," in IEEE International Workshop on Robot and Human Interactive Communication. ROMAN 2005., Aug 2005, pp. 347-352.

[19] J. Bitchener, "Evidence in support of written corrective feedback," Journal of Second Language Writing, vol. 17, no. 2, pp. $102-118$, 2008.

[20] N. Dahlbäck, A. Jönsson, and L. Ahrenberg, "Wizard of oz studies: Why and how," in Proceedings of the 1st International Conference on Intelligent User Interfaces, ser. IUI '93. New York, NY, USA: ACM, 1993, pp. 193-200.

[21] P. H. Kahn Jr, T. Kanda, H. Ishiguro, N. G. Freier, R. L. Severson, B. T. Gill, J. H. Ruckert, and S. Shen, "'robovie, you'll have to go into the closet now": Children's social and moral relationships with a humanoid robot." Developmental psychology, vol. 48, no. 2, p. 303, 2012. 